[3] Draganov DI, Teiber JF, Speelman A et al. Human paraoxonases (PON1, PON2, and PON3) are lactonases with overlapping and distinct substrate specificities. J Lipid Res. 2005;46:1239-47.

Acknowledgements: None.

Disclosure of Interest: None declared

DOI: 10.1136/annrheumdis-2017-eular.3459

\section{THU0259 RESPIRATORY SYMPTOMS IN PRIMARY SJÖGREN'S SYNDROME, A CROSS-SECTIONAL STUDY OF THE OASIS COHORT}

A. Dumusc ${ }^{1}$, B. Fisher ${ }^{2}$, F. Barone ${ }^{2}$, A. Richards ${ }^{3}$, A. Poveda ${ }^{3}$, J. Higham ${ }^{3}$, S. Rauz ${ }^{2}$, S. Bowman ${ }^{1} .{ }^{1}$ University Hospitals Birmingham NHS Foundation Trust; ${ }^{2}$ Institute of Inflammation and Ageing, University of Birmingham;

${ }^{3}$ Birmingham Dental Hospital, Birmingham, United Kingdom

Background: In previous studies, 5 to $35 \%$ of patients with primary Sjögren's syndrome (pSS) are reported to have respiratory symptoms (RS). Pulmonary involvement varies from a dry cough due to airway dryness to life-threatening interstitial lung disease.

Objectives: To evaluate RS prevalence in patients with pSS and compare characteristics of pSS patients with and without RS to those in patients without pSS suffering from ocular or oral dryness.

Methods: Cross-sectional study of patients at the time of their inclusion in the OASIS cohort between 2014 and September 2016. This UK prospective research cohort includes patients with suspected pSS or known pSS and aims to collect long-term high quality data with regular clinical, dental and ophthalmological assessments. We asked systematically all the patients if they had any RS. In case of clinically significant RS, pulmonary function tests (PFTs) were requested, and if needed, a high-resolution chest tomography (HRCT) was performed. We included in the analysis only patients fulfilling the AECG (2002) criteria for pSS and excluded patients with secondary Sjögren's syndrome. Characteristics of pSS patients with and without RS and non-pSS patients with sicca symptoms were compared. For statistical analysis, we used unpaired t test, Mann-Whitney test, Fisher's exact test and Chi-square test when appropriate. $\mathrm{P} \leq 0.05$ was considered statistically significant.

Results: Among the 157 patients included in the cohort, 70 fulfil the AECG criteria for pSS and 63 have sicca symptoms without pSS. In the pSS/sicca non-pSS groups, $25.7 \% / 15.9 \%$ had RS (cough $10.0 \% / 7.9 \%$ and breathlessness $15.7 \% / 6.3 \%$ ) and $5.7 \% / 1.6 \%$ an abnormal chest clinical examination respectively. PSS patients with pre-existing lung disease $(n=11)$ had significantly more RS than pSS patients without it $(n=59): 54.5 \%$ versus $20.3 \%(p=0.03)$

PSS patients with RS or abnormal chest clinical examination $(n=21)$ had a higher ESSDAl index value (mean $+S D$ ) than patients without them $(n=49)(7.8+5.7$ versus $5.0 \pm 4.9, p=0.04$ ), essentially due to a higher constitutional domain score $(1.7 \pm 2.1$ versus $0.6 \pm 1.5, p=0.01)$ and a higher respiratory domain score $(1.3 \pm 2.8$ versus $0, p<0.01$ ). They also had a higher ESSPRI index value (mean $\pm S D$ ), which is a patient reported outcome: $7.4 \pm 1.7$ versus $6.0 \pm 2.1(p=0.05)$. There were no differences between pSS patients with and without RS in terms of demographic characteristics, objective measurements of tear and saliva production, histological focus scores and auto-immunity profiles.

In this same group of pSS patients, 10 PFTs and 9 HRCTs were requested and showed abnormal results in $60.0 \%$ and $55.6 \%$ respectively. A reduced gas transfer was the most common finding in PFTs (DLCO $\mathrm{mM} / \mathrm{min} / \mathrm{kPa}$, \% predicted value, mean \pm SD: $66.7 \pm 11.7$ ). Among these patients, 2 patients were diagnosed with interstitial lung disease. Both had abnormal PFTs and HRCT.

Conclusions: One third of pSS patients presented with respiratory symptoms or abnormal chest clinical examination at inclusion in our cohort. These patients had higher ESSDAI and ESSPRI index values but did not differ in terms of objective saliva and tear production measurements and auto-antibody profile. Reduced gas transfer was the most common abnormal finding in PFTs.

Disclosure of Interest: None declared

DOI: 10.1136/annrheumdis-2017-eular.4759

\section{THU0260 LOW PLASMA CONCENTRATIONS OF APOLIPOPROTEIN M CORRELATE TO DISEASE ACTIVITY AND ENDOTHELIAL DYSFUNCTION IN SLE}

A. Bengtsson ${ }^{1}$, H. Tydén ${ }^{1}$, C. Lood ${ }^{1}$, B. Gullstrand ${ }^{1}$, B. Dahlbäck ${ }^{2}$, A. Jönsen ${ }^{1}$ ${ }^{1}$ Rheumatology, Institution of Clinical Sciences, Lund University, Lund; ${ }^{2}$ Clinical Chemistry, Institution of Translational Medicine, Malmö, Sweden

Background: ApoM is an antiatherogenic and vasculoprotective $25 \mathrm{kDa}$ apolipoprotein suggested to play a role in keeping endothelial barrier integrity. Objectives: The aims of the current study were to determine the impact of SLE disease activity on apoM levels and investigate if apoM levels reflect endothelial function in SLE.

Methods: Plasma concentrations of apoM were measured with ELISA in two SLE cohorts, all patients fulfilling $\geq 4$ American College of Rheumatology (ACR) classification criteria for SLE, and 100 healthy controls (HC). Patients in cohort I had active disease as evaluated with SLEDAI scores. In cohort II endothelial function was measured by EndoPAT 2000 and correlated to apoM levels. A low Reactive Hyperemia Index (RHI) value indicated endothelial dysfunction (ED).
Results: In cohort I, the plasma levels of apoM were found to be significantly decreased in SLE $(p<0.0001)$, and the apoM concentrations correlated inversely to disease activity (SLEDAI, $r=-0.29, p=0.0063$. ApoM was also significantly lower in patients with active nephritis, leukopenia, anti-DNA antibodies or rash compared to patients without these manifestations.

In cohort II, using linear regression analysis, there was a positive correlation between apoM levels and the RHI value, indicating endothelial dysfunction, in the younger SLE patients: $\beta=0.94 \mathrm{Cl} 95 \% 0.22,1.65 \mathrm{r}=0.32 \mathrm{p}=0.011$

Conclusions: SLE related inflammation may have an impact on lower plasma apoM, which may affect the endothelium and the process towards cardiovascular disease.

Disclosure of Interest: None declared

DOI: 10.1136/annrheumdis-2017-eular.5757

\section{THU0261 PREGNANCY COURSE AND OUTCOME IN SLE PATIENTS COMPARED TO PATIENTS WITH OTHER CONNECTIVE TISSUE AND INFLAMMATORY RHEUMATIC DISEASES - DATA FROM A PROSPECTIVE COHORT STUDY}

A. Strangfeld ${ }^{1}$, C. Bungartz ${ }^{1}$, A. Weiß ${ }^{1}$, M. Schneider ${ }^{2}$, J. Richter $^{2}$, A. Zink ${ }^{1,3}$, R. Fischer-Betz ${ }^{2} .{ }^{1}$ German Rheumatism Research Centre, Berlin; ${ }^{2}$ Department of Rheumatology \& Hiller Research Unit, University Hospital, Düsseldorf;

${ }^{3}$ Charité University Medicine, Berlin, Germany

Background: Patients with systemic lupus erythematosus (SLE) are at increased risk for pregnancy complications and adverse pregnancy outcomes. During the past decades, advances in drug treatment and management during pregnancy made successful pregnancy in patients with SLE possible. Less is known about pregnancy course in other connective tissue diseases (OCTD).

Objectives: To compare pregnancy courses and outcomes in SLE patients with those in OCTD patients and patients with other inflammatory rheumatic diseases. Methods: The German Rhekiss register is designed as nationwide, web-based longitudinal observational cohort study. Pregnant patients with confirmed diagnose of inflammatory rheumatic disease are eligible to be enrolled until the 20th week of pregnancy regardless of drug treatment. At baseline, sociodemographic parameters, prior pregnancies, comorbidities and antibody status are reported. During pregnancy, rheumatologists and patients report drug treatments, course of the maternal disease, development of fetus and complications once per trimester. After delivery, the pregnancy outcome and child development during the first two years of life are collected.

Results: Until October 2016, data of 392 patients were available and grouped according to their disease in SLE patients, those with other connective tissue disease (OCTD) and patients with all other diagnoses (allO). 121 women had already completed their pregnancy with known outcome. Of them, most patients in the OCTD group were diagnosed with undifferentiated connective tissue disease

\begin{tabular}{|c|c|c|c|}
\hline & SLE & $\begin{array}{c}\text { Other connective } \\
\text { tissue diseases }\end{array}$ & $\begin{array}{l}\text { All other } \\
\text { diagnoses }\end{array}$ \\
\hline \multicolumn{4}{|c|}{ Patient characteristics at enrolment } \\
\hline Pregnancies, $\mathbf{n}$ & 85 & 71 & 236 \\
\hline Maternal age [vears] & $31.8(4.4)$ & $32.9(3.9)$ & $32.4(4.3)$ \\
\hline Discose duration [veors] & $7.3(5.9)$ & $5.8(6.05)$ & $8.3(7.6)$ \\
\hline $\mathrm{BMI}>30, n(\%)$ & $4(8.7)$ & $1(2.6)$ & $10(8)$ \\
\hline $\begin{array}{l}\text { Disease activity (physician global) } \\
{[0-10] \text { in the first trimester }}\end{array}$ & $1.5(1.3)$ & $1.7(1.5)$ & $2.6(2.2)$ \\
\hline Rheumatold factor positive, $n(\%)$ & $9(14.8)$ & $12(25.5)$ & $48(34.5)$ \\
\hline Lupus anticoagulant positive, $n$ & 6 & 1 & 1 \\
\hline Anticardiolipin antibody positive, $n$ & 13 & 3 & 1 \\
\hline Anti-B2-GP-1 positive, $n$ & 10 & 3 & 2 \\
\hline Antiphospholipidsyndrome, $n$ & 10 & 1 & 1 \\
\hline SLEOAI & $1.7(2.3)$ & 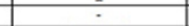 & $=$ \\
\hline RAID $[0-10]$ & $1.8(1.6)$ & $1.9(2.0)$ & $2.1(2.0)$ \\
\hline \multicolumn{4}{|c|}{ Outcomes of pregnancies } \\
\hline Completed pregnancies, $\mathbf{n}$ & 32 & 25 & 64 \\
\hline Miscarriages, $n$ (wk of gestation) & 2 (wk 9/12), 1 elective (w/k21) & $2($ wok $14 \& 21)$ & $2(w k 5 \& 10)$ \\
\hline \multicolumn{4}{|c|}{ No. of patients with flares during preenancy } \\
\hline $1-2$ flores & tonst & 5 & 37 \\
\hline $3-4$ flares & 0 & 0 & 10 \\
\hline $5-6$ flares & 0 & 0 & 4 \\
\hline \multirow{2}{*}{$\begin{aligned} & \text { Life births, n: preterm }\left(<37^{n n}\right. w(k) \\
& \text { at term }\left(\geq 37^{n n} w(k)\right.\end{aligned}$} & $5+2 \times$ twins & $2+1 \times$ twins & $7+1 \times$ twins \\
\hline & $19+3 \times$ twins & 20 & $53+1 \times$ twins \\
\hline $\begin{array}{l}\text { Mean birth weight (gtamm) of } \\
\text { singletons born ot term }\end{array}$ & 3123 & 3234 & 3477 \\
\hline $\begin{array}{l}\text { Serious complications during } \\
\text { pregnancy (n patients) }\end{array}$ & $\begin{array}{|lc|}\text { HELLP Syndrome } & (1) \\
\text { severe preeclampsia } & (1) \\
\text { serious bleedings } & (2) \\
\text { preterm lobour } & (1) \\
\text { serious infection } & (2) \\
\text { thrombotic embolism } & \text { (1) }\end{array}$ & $\begin{array}{lr}\text { HELLP Syndrome } & \text { (2) } \\
\text { preeclampsia } & \text { (2) } \\
\text { preterm rupture of } \\
\text { membranes } & \text { (1) } \\
\text { serious infection } & \text { (1) }\end{array}$ & none \\
\hline $\begin{array}{l}\text { Non-serious complications } \\
\text { (n patients) }\end{array}$ & $\begin{array}{|ll|}\text { gestational diabetes } & (2) \\
\text { infections } & \text { (1) }\end{array}$ & $\begin{array}{|ll|}\text { Eest, diabetes } & \text { (1) } \\
\text { infections } & \text { (1) }\end{array}$ & $\begin{array}{l}\text { Eest, diabetes (3) } \\
\text { infections (4) }\end{array}$ \\
\hline $\begin{array}{l}\text { Congenital malformation / } \\
\text { complication }\end{array}$ & $\begin{array}{l}\text { multiple anomalies } \rightarrow \\
\text { elective termination } \\
\text { polatine cleft (suspected } \\
\text { Pierre-Robin-Syndrome) } \\
\text { bamangisona at leg } \\
\text { congenital megaureter }\end{array}$ & $\begin{array}{l}\text { sacral agenesis } \\
\text { bexadactulus, (both } \\
\text { sides) }\end{array}$ & $\begin{array}{l}\text { hip dysplasia } \\
\text { sacral } \\
\text { bămanzioma }\end{array}$ \\
\hline Postpartal maternal complications & $\begin{array}{l}\text { cerebral insult } \\
\text { serious pyelonephritis } \\
\text { hypertensive crisis }\end{array}$ & none & none \\
\hline $\begin{array}{l}\text { Neonatal complications } \\
\text { (n children) }\end{array}$ & $\begin{array}{ll}\text { serious infections } & \text { (3) } \\
\text { lethal sepsis } & \text { (1) } \\
\text { serious ieterus } & \text { (1) }\end{array}$ & $\begin{array}{l}\text { serious infection (3) } \\
\text { serious respiratory } \\
\text { distress (3) } \\
\text { hypoglycremia (1) }\end{array}$ & $\begin{array}{l}\text { non-serious } \\
\text { infection (1) } \\
\text { serious respl- } \\
\text { ratony distress (1) }\end{array}$ \\
\hline
\end{tabular}


(9), Sjögren Syndrome (5) and mixed connective tissue disease (5). The allO group included rheumatoid arthritis (28), psoriatic arthritis (10), spondyloarthritis (11), and JIA (8). The proportion of children born at term was lowest in patients with SLE $(79 \%)$, compared to OCTD $(91 \%)$ and allO patients $(88 \%)$. The table shows selected baseline and outcome parameters.

In early pregnancy, more patients with SLE reported low disease activity and a higher proportion was diagnosed by the rheumatologist as having mild disease than in the other diagnoses groups. During pregnancy, flares occurred rarely in SLE and OCTD patients, whereas a substantial proportion of patients in the allO group had multiple flares. However, serious complications during and after pregnancy occurred more often in SLE and OCTD patients, as well as congenital anomalies and complications. Due to the low number of events and completed pregnancies, associations to suspected risk factors couldn't be analyzed yet. Conclusions: Although most patients with SLE or OCTD had a favorable course and outcome of pregnancy, compared to patients with other inflammatory rheumatic diseases substantially more complications and adverse pregnancy outcomes occurred. The association to specific risk factors predicting adverse pregnancy outcomes could not yet be analyzed. At the time of the EULAR congress we expect at least twice as much completed pregnancies.

All patients with SLE and OCTD should be tightly screened during pregnancy with timely and adequate adjustment of drug treatments.

Acknowledgements: Rhekiss is a collaborative project of the DRFZ Berlin and the Rheumazentrum Rhein-Ruhr e.V. Düsseldorf, jointly funded by both institutions.

Disclosure of Interest: None declared

DOI: 10.1136/annrheumdis-2017-eular.6714

\section{THU0262 CHANGES IN SONOELASTOGRAPHIC CHARACTERISTICS IN SJÖGREN'S SYNDROME - A FIVE-YEAR FOLLOW UP}

B. Hofauer, M. Bas, N. Mansour, A. Knopf. Otorhinolaryngology/Head and Neck Surgery, Klinikum Rechts Der Isar, Technical Universitiy Munich, Munich, Germany

Background: The role of sonography in the evaluation of salivary gland alterations in patients with suspected Sjögren's Syndrome (SS) and its benefit with regard to the diagnosis is part of continuing investigation. Studies on sonoelastographic alterations in the salivary glands of patients with SS have been published during the last years and were able to prove significant differences compared to patients with sicca-symptoms without fulfilling the AECG classification criteria [1,2]. The available knowledge on longitudinal changes in sonoelastographic characteristics is still limited.

Objectives: Which variations of sonoelastographic salivary gland alterations can be observed during the five-year follow up of patients with primary Sjögren's Syndrome?

Methods: Patients with primary Sjögren's Syndrome (pSS) diagnosed according to the AECG classification criteria were included in this study. The EULAR SS Patient Reported Index (ESSPRI) was applied for the evaluation of patient's symptoms and the EULAR SS Disease Activity Index (ESSDAI) for systemic features. During 2011 and 2016 the sonoelastographic alterations of the salivary glands in patients with primary Sjögren's Syndrome were evaluated. Acoustic Radiation Force Impulse (ARFI) imaging (=shear wave velocity), Real Time Tissue Elastography (RTTE) and Virtual Touch Tissue Imaging (VTTI) were applied for the sonoelastographic evaluation in addition to B-Mode sonography (BMUS). Results of BMUS, RTTE and VTTI were graded with appropriate scoring systems. Results: Fifty patients diagnosed with pSS were included ( 45 female, age: 56 years $S D=16)$. In 2011 the mean ESSPRI score was $8.3(S D=4.6)$ and the mean ESSDAI score was $5.6(S D=7.5)$. Initially, the mean ARFI value of parotid glands was $2.99 \mathrm{~m} / \mathrm{s}(\mathrm{SD}=0.93)$ and the mean ARFI value of the submandibular glands was $2.15 \mathrm{~m} / \mathrm{s}(\mathrm{SD}=0.57)$. Clinical examination and sonoelastographic evaluation was repeated after five years in 2016, revealing a mean ESSPRI score of 6.1 $(S D=3.2, p=0.002)$ and a mean ESSDAl score of $4.6(S D=7.0, p<0.001)$. After five years a significant decline of ARFI values could be observed in the parotid gland $(2.33 \mathrm{~m} / \mathrm{s}, \mathrm{SD}=0.70, \mathrm{p}<0.001)$ while no significant changes of the ARFI of the submandibular gland could be observed. Results of RTTE and VTTI did not change significantly. The mean time interval between onset of first symptoms and first sonographic examination in 2011 was 57.3 months ( $S D=60.8$ ).

Conclusions: The five-year sonoelastographic follow up of salivary gland alterations in patients with pSS revealed a decline in the severity of sonoelastographic alterations of the parotid gland in ARFI imaging, indicating a certain capability for modulation of salivary gland affection in pSS.

References:

[1] Hofauer B et al. Sonoelastographic Modalities in the Evaluation of Salivary Gland Characteristics in Sjögren's Syndrome. Ultrasound Med Biol 2016;2) Knopf $A$ et al. Diagnostic utility of Acoustic Radiation Force Impulse (ARFI) imaging in primary Sjoegren's syndrome. Eur Radiol 2015.

Disclosure of Interest: None declared

DOI: 10.1136/annrheumdis-2017-eular.6436

\section{THU0263 PREVALENCE OF REMISSION AND ITS EFFECTS ON ORGAN DAMAGE AND QUALITY OF LIFE IN CHINESE PATIENTS WITH SYSTEMIC LUPUS ERYTHEMATOSUS}

C.C. Mok, L.Y. Ho, S.M. Tse, K. Chan. Medicine, Tuen Mun Hospital, HK, Hong Kong

\section{Background:}

Objectives: To study the effect of disease remission on organ damage and quality of life in Chinese patients with systemic lupus erythematosus (SLE).

Methods: Patients who fulfilled the ACR classification for SLE were studied. Their remission status at last visit was determined by the European consensus (DORIS definition): (1) Complete remission (clinical SLEDAI=0, serology inactive); and (2) Clinical remission (clinical SLEDAl=0, serology active). These two categories were further divided into those who required ongoing immunosuppressive treatment (prednisone $\leq 5 \mathrm{mg} / \mathrm{d}$ or other immunosuppressive agents) and who did not. The increase in SLE organ damage (SDI) score since 5 years prior to recruitment was compared between patients who were and were not in remission for $\geq 5$ years. Participants were randomly selected for assessment of quality of life by using both the validated version of SF36 and the LupusPRO (version 1.8) and comparison was made between those who did and did not achieve remission for $\geq 5$ years by the independent Students' t-test.

Results: 769 SLE patients were studied (92\% women; age $46.4 \pm 14.6$ years, SLE duration $12.6 \pm 8.1$ years). At last visit, clinical remission was present in $259(33.7 \%)$ patients (median 43 months) and complete remission (clinically and serologically inactive) was present in 280 (36.4\%) patients (median 51 months). Clinical/complete remission for $\geq 5$ years was achieved in $64(8.3 \%)$ and 129 $(16.8 \%)$ of the patients, respectively. $53(6.9 \%)$ patients in remission $\geq 5$ years were taken off all medications including HCQ (drug-free). Compared with patients who did not remit, those remitted $\geq 5$ years were older $(49.9 \pm 13.2$ vs $45.7 \pm 15.8$; $\mathrm{p}=0.004$ ), and had significantly lower prevalence of renal involvement, leukopenia or thrombocytopenia. Significantly fewer patients who remitted for $\geq 5$ years were maintained on prednisolone compared to others $(31 \%$ vs $68 \% ; p<0.001)$. The increase in SDI scores over the preceding 5 years was $0.17 \pm 0.53$ in patients who had complete/clinical remission off-therapy (except $\mathrm{HCQ}$ ) for $\geq 5$ years $(\mathrm{N}=88$ ), $0.25 \pm 0.51$ in those remitted for $\geq 5$ years but maintained on immunosuppressive medications $(\mathrm{N}=105), 0.41 \pm 0.84$ in those remitted for $<5$ years $(\mathrm{N}=346)$ and $0.67 \pm 1.10$ in those who did not remit $(N=230)$, respectively. The increase in SDI was statistically higher in those remitted for $>5$ years than $<5$ years $(p=0.007)$ or those who did not remit $(p<0.001)$. Logistic regression showed that patients with remission for $<5$ years or who did not remit had an increase in the risk of new damage accrual as compared to those with remission for $>5$ years (OR 2.42 [1.50-3.89]; $p<0.001$ ), adjusted for age, sex, SLE duration, SDI scores 5 years prior and the daily maintenance prednisolone dose at last visit. Among 453 patients who had QOL assessment, remission for $\geq 5$ years was associated with significantly higher higher physical component and mental component scores of the SF36 than those who did not remit. Patients with remission for $\geq 5$ years had significantly higher scores in the individual health-related domains (except cognition) of the LupusPRO than those who did not remit.

Conclusions: Durable remission can be achieved in a quarter of patients with SLE. Patients with remission for $\geq 5$ years have significantly less damage accrual and better QOL. Prolonged remission is an appropriate parameter for outcome assessment in SLE.

Disclosure of Interest: None declared

DOI: 10.1136/annrheumdis-2017-eular.3947

\section{THU0264 RESPONSIVENESS OF LUPUSPRO V1.8 AMONG CHINESE PATIENTS WITH LUPUS}

C.C. Mok ${ }^{1}$, J. Block ${ }^{2}$, M. Jolly ${ }^{2} .{ }^{1}$ Medicine, Tuen Mun Hospital, HK, Hong Kong; ${ }^{2}$ Medicine and Behavorial Sciences, Rush University Medical Center, Chicago, United States

Background: LupusPRO v1.7 is a patient reported outcome tool for patients with systemic lupus erythematosus (SLE) that has undergone psychometric validation and responsiveness studies in the US.

Objectives: To report results on responsiveness of LupusPRO among Chinese patients with SLE.

Methods: 430 patients with SLE meeting the ACR classification criteria were recruited in Hong Kong, China at a single center for this observational study. LupusPRO scores from two visits one year apart were analyzed for responsiveness and Minimal Clinically Important Difference (MCID) against patient report and physician assessed anchors of changes in health. Two patient reported anchors were used (Global change in health and item 2 of Short Form 36 form). Physician assessed anchors of change in health were disease activity (Physician global assessment-PGA, SELENA-SLEDAI) and damage (SLICC-SDI/ACR). Change in PGA of $\geq 0.3$ and SELENA-SLEDAI of $\geq 4$ in either direction was used to define worsening in disease activity. Our primary outcomes of interest were was summary $\mathrm{HRQOL}$ and $\mathrm{HRQOL}$ domains, as non HRQOL domains tend not to change over short time periods. Analysis of variance was used to compare changes in LupusPRO summary and domain scores against the anchors.

Results: Mean (SD) age of participants was 42 (14) years. Ninety five percent were women. Mean (SD) PGA, SELENA-SLEDAI and SDI at baseline were $0.5(0.5), 2.9(3.0)$ and $0.7(1.2)$ respectively. Summary HRQOL, and HRQOL 